\title{
Computer Assisted Collaborative Concept Mapping in Engineering Education
}

\author{
Uday N. Gaitonde, Bhalachandra L. Tembe, and Sachin K. Kamble
}

\begin{abstract}
The present study evaluates a collaborative concept-mapping technique in the third year mechanical engineering undergraduates in order to examine students' performance and attitudes towards an experimental teaching method in the topic of introduction to the internal combustion engines (IICE). This study used a quasi experimental design, incorporating both quantitative and qualitative techniques. There were 90 students involved in the study divided into two groups. The experimental group was assigned collaborative concept maps and the control group was assigned individual concept maps. The findings indicated that the two teaching methods resulted in a significant difference with respect to students' test scores. Collaborative concept maps promoted higher quality of maps and enhanced active learning. Collaborative concept mapping to learn the topic of IICE could increase the possibility of discussion between students, thus enhancing better organization and understanding of the subject. Students were positive towards the collaborative concept maps.
\end{abstract}

Index Terms-Active learning, collaborative learning, concept mapping, IICE.

\section{INTRODUCTION}

One of the goals of engineering education is to enhance students' ability to apply their previous knowledge to new domains or new topics. Active learning has attracted considerable attention over the past several years in engineering education. Active learning is defined as any teaching- learning strategy that engages students in the learning process. In active learning, students are engaged in meaningful learning activities and in the process of thinking about the activity [1]. Collaborative learning is an active-learning strategy in which students work together in small groups towards a common goal. Concept mapping is one of the most useful cognitive strategies, in which students synthesize their actual states of knowledge during the learning process [2]. One of the most promising applications of concept mapping is its integration into collaborative learning activities. Researchers are exploring the use of collaborative concept mapping (CCM) to enhance learning in engineering education [3]-[6].

Concept maps (CM) have been used as a teaching-learning strategy to support learning and as a measure to represent knowledge. CM is a recognized area in educational research

Manuscript received December 3, 2015: revised March 16, 2016.

Uday N. Gaitonde is with the Department of Mechanical Engineering, Indian Institute of Technology, Bombay, India (e mail: gaitonde@iitb.ac.in).

Bhalachandra L. Tembe is with the Department of Chemistry, Indian Institute of Technology, Bombay, India (e mail: bltembe@chem.iitb.ac.in).

Sachin K. Kamble is with the Department of Mechanical Engineering, Chhatrapati Shivaji Maharaj Institute of Technology, Panvel, India (e mail: skkamble@yahoo.com). and is applied in domains such as science, engineering, economics and business settings.

In order to enhance the quality and impact of learning, educational institutes are exploring the role of collaborations in learning among students.

This paper reports on a case study of a collaborative concept mapping process in engineering education in Mumbai University.

\section{CONCEPT MAPPING}

According to Chang, Sung, and Chen (2001), concept mapping is a learning strategy consistent with constructivist learning theory [7]. It is a form of visualization tool which helps students visualize interrelationships among concepts [8]. Implementing concept mapping into the teaching and learning process opens up new opportunities for constructivist learning [9].

Concept maps are graphical tools to organize and represent knowledge in a network of hierarchically ordered concepts [10]. Concept mapping is a tool that can engage students in meaningful learning processes. Further, concept mapping promotes meaningful learning and retention of knowledge for long periods of time and helps students to negotiate meaning [11], [12].

Concept maps can be created by individuals or small groups; the latter being referred to as collaborative concept mapping (CCM). The stages of CCM proceed in the same way as individual concept mapping [10]. First, a clear knowledge domain is established by presenting a focus question or idea that is to be addressed during the concept mapping. Then key concepts are generated by students in response to the focus question or idea. The concepts are arranged in a hierarchical order from the most general to the most specific concepts and they contain cross-links with linking words to form propositions. These linking words or phrases connect concepts to form a meaningful statement. The process of creating maps is a dynamic one. The position of concepts and the cross-links can be rearranged as required and a map is ready for revision.

Concept maps use visual representation of knowledge structure [12], [13]. In creating concept maps, students learn to integrate the relationship between each concept. In organizing concepts, students will have more opportunities to self-evaluate their knowledge structure. Therefore, concept mapping can be used as metacognitive strategy for learning in addition to meaningful learning [14]. Hence, concept mapping is a tool to help students learn how to learn [15], [16]. Research has shown that with collaborative learning, students can refine and improve their own knowledge structures. 
In collaborative concept mapping, students are creating concept maps in small groups. With the development of information and communication technologies (ICT) and concept mapping softwares, collaborative concept mapping has become even more popular.

Fischer, Bruhn, Grasel, and Mandl, (2002) stated that collaborative processes can enhance students knowledge construction more effectively than individual processes [17]. According to Lumpe and Staver (1995), collaboratively creating propositions using paper and pencil in small groups can have positive effects on student achievements [18].

In a process of collaboration, the role of the student can evolve from being a passive learner to becoming an active, social learner. Students' previous knowledge and ideas of concepts are challenged during collaboration, and learning builds on what students have already constructed in other contexts [17], [19].

In collaborative learning, concept maps provide help to build the knowledge structure. Collaborative concept maps increase interaction between students and allow sharing of meaning of concepts. While drawing of concept maps, students activate their previous knowledge and build knowledge structure though information exchanges [10], [20]-[23].

Concept mapping can be generated on personal computers using computer softwares [9], [24]-[26]. The use of concept mapping tools such as $\mathrm{CMAP}^{\mathrm{TM}}$, Inspiration ${ }^{\mathrm{TM}}$ and Freemind $^{\mathrm{TM}}$ enable students to connect the ideas or concepts that they are studying and to label and establish the relationships between those concepts [27], [28]. Anderson-Inman (1996) shows that computer-based tools make the learning process more easy going to students, and it removes the frustration felt by students while generating concept maps and revising concept maps using paper and pencil [29].

In summary, various researchers have explored the effects of concept mapping strategy on paper, concept mapping on computers, and concept mapping individually and collaboratively on paper. Such studies have shown that concept mapping positively affects students' learning of concepts. Computer-generated concept mapping also positively affects students' learning of concepts beyond concept mapping on paper. In addition, literature shows that collaboratively generating concept maps on paper positively affects learning beyond individually generating concept maps Therefore, the next step is to determine which strategy is most appropriate: Computer-based individually-generated concept maps or computer-based collaboratively generated concept maps.

CCM can provide more stimuli to enhance learning than individual concept mapping [30]. Understanding individual learning and group learning is the key to help students to benefit most from the use of concept mapping activity. In this study, we investigate how different approaches of making concept mapping influence learning. Specifically, how third year mechanical engineering students learn the topic of introduction to the internal combustion engines (IICE) when they construct concept maps alone and when they construct concepts maps in groups.

\section{RESEARCH QUESTIONS}

The primary focus of this study was to examine the use and effectiveness of collaborative concept mapping as a teachinglearning strategy in the teaching of the IICE. Specifically, this study addresses the following research questions:

1) Does the use of collaborative concept mapping in the teaching of the IICE affect significantly the achievements of students in the experimental group who construct concept maps?

2) What is the differential role, if any of CCM at different levels of Bloom's taxonomy of learning?

3) Will there be any effect of using collaborative concept mapping on students' attitudes toward the topic of IICE?

Overall, this study builds on the use of concept mapping as a teaching- learning strategy. In the following sections, we describe the study, present the results and analyze them. Finally, we give our recommendations.

\section{METHOD}

This is a quasi-experimental study conducted in University of Mumbai, India with the participation of 90 students of third year mechanical engineering students. We divided these students in two groups randomly, into experimental and control groups. The experimental group $(N=44)$ was taught with the collaborative concept maps and the control group ( $N$ $=46$ ) was taught with individual concept maps. The students in the experimental group were randomly divided into groups of 3 to 4 students. Participants spent an hour per week for two weeks on this experiment to learn how to use computer software (Inspiration Tool) to create concept maps for the topic of IICE individually and collaboratively in groups. In the first week, the teacher (who taught the class) explained the idea of concept mapping and the use of Inspiration Tool. In the following week, the teacher explained and demonstrated the strategies of creating concept maps. The lessons included how to identify key concepts and relations, how to arrange them into a hierarchy, and how to present the concepts with branches and cross-links. The participants also practiced concept mapping with various examples from other topics.

\section{INSTRUMENTS}

The dependent variable in this study is the students' achievement in the topic of IICE. We used two objective tests to measure achievements of the students. The pretest measured students' pre-requisite knowledge in the topic of thermal engineering (30 questions). The second test (posttest) measured students' achievement in the topic of IICE at the conclusion of the study. A satisfaction questionnaire (to be discussed below in a later section) was given to the students at the end of the study to examine the attitude of students towards active learning methods to learn the topic of IICE. The items or questions in the questionnaire were rated on a five-point Likert scale from 'strongly disagree' to 'strongly agree'. The Cronbach alpha coefficient of the instrument was 0.81 .

Bloom's taxonomy (1969) was used to ensure that test items in the post test were at different cognitive levels. The 
test questions used in this study are at the knowledge, comprehension, application and numerical level questions. In the post test, there were total 40 questions related to the topic of IICE. According to Bloom's taxonomy, the distribution of the questions related to the topics of IICE in the post test is as shown in Table I.

TABLE I: DISTRIBUTIONS OF THE QUESTIONS ACCORDING TO BLOOM's TAXONOMY

\begin{tabular}{cc}
\multicolumn{2}{c}{ TAXONOMY } \\
\hline \hline Level & Third year mechanical engineering students \\
\hline Knowledge & 10 \\
Comprehension & 10 \\
Application & 10 \\
Numerical & 10 \\
Total questions & 40 \\
\hline \hline
\end{tabular}

The reliability KR-20 of the pretest was 0.75 while that of the post test of the topic of IICE was 0.77 .

\section{PROCEDURE}

The study was carried out in three sessions. In the first two (60 minutes each), students received instructions on concept mapping. In the first session, the importance and use of concept maps were explained and some of the applications were also discussed.

In the second session, a practice of modeling for concept mapping on contents from other domains on computers was carried out. A practice concept map from everyday life was taken as an example. In this session, the prior knowledge questionnaire of the thermal engineering was also administered. In the third session, a 60 minutes collaborative learning session was held. At the beginning, objectives and instructions to perform the task were explained. Subsequently, groups had 60 minutes to develop collaborative concept maps and finally, participants answered the self-assessment questionnaire on collaboration in teams. The students created concept maps on Inspiration tool and later they were compared to an expert map generated by the teacher.

\section{RESULTS}

\section{A. Pretest}

The mean score of the pretest for the experimental group was found to be 11.36, while that of the control group was found to be 11.52 out of a maximum possible score of 30 . A $t$-test for independent samples showed that there were no significant differences between the two groups $(t=0.318, p$ > $0.05)$. As there were no significant differences in the pretest in the experimental group and the control group, it was assumed that the two groups were having equivalent means. In the present work, the level of significance ( $\alpha$ level) is taken to be 0.05 .

\section{B. Post Test}

Table II presents the means and standard deviations of the post test results for the control and experimental groups. These results include the scores at the knowledge level (KL), comprehension level (CL), application level (AL) and numerical level (NL) questions along with the total scores on the topic of IICE achievement posttest (TL).

A $t$-test for independent samples was carried out to test whether the experimental and control groups differed significantly on the posttest achievement in the topic of IICE (TL-test). Significant differences were found at the total scores (TL) $(t=2.27, p<0.05)$.

In addition, a t-test for independent samples was carried out to test whether the scores of the experimental and control groups differed significantly on the questions at different cognitive levels. No significant difference was found for the questions at the knowledge level $(t=0.08, p>0.05)$. Significant difference was found at the comprehension level $(\mathrm{t}$ $=3.16, p<0.05)$. At the application-and-above level $(t=1.14$, $p>0.05)$ and numerical level $(t=1.59, p>0.05)$, no significant differences were found (Table II).

TABLE II: MEANS AND STANDARD DEVIATIONS OF THE PARAMETERS USED IN THE STUDY FOR THE EXPERIMENTAL AND CONTROL GROUPS

\begin{tabular}{ccccccccc}
\hline \hline \multicolumn{3}{c}{ Experimental group } & \multicolumn{7}{c}{ Control group } & $\mathrm{t}$ & $\mathrm{p}$ \\
\hline Test & $\mathrm{N}$ & Mean & $\mathrm{SD}$ & $\mathrm{N}$ & Mean & $\mathrm{SD}$ & & \\
$\mathrm{KL}$ & 44 & 6.36 & 1.65 & 46 & 6.39 & 1.34 & 0.08 & 0.931 \\
$\mathrm{CL}$ & 44 & 5.79 & 1.53 & 46 & 4.78 & 1.50 & 3.16 & $0.002^{*}$ \\
$\mathrm{AL}$ & 44 & 4.27 & 1.35 & 46 & 3.91 & 1.60 & 1.14 & 0.254 \\
$\mathrm{NL}$ & 44 & 3.36 & 1.14 & 46 & 2.89 & 1.62 & 1.59 & 0.115 \\
$\mathrm{TL}$ & 44 & 19.79 & 3.12 & 46 & 18.00 & 4.25 & 2.27 & $0.025^{*}$ \\
\hline \hline
\end{tabular}

Note: $p<0.05^{*}$

KL-test $=$ scores of knowledge level questions in the post-test (the maximum score is 10).

CL-test $=$ scores on comprehension level questions in the post-test (maximum score is 10).

AL-test $=$ scores of the application level questions in the post-test (Maximum score is 10).

NL-Test $=$ scores of the numeric level questions in the post-test (Maximum score is 10).

TL-test $=$ Total scores in the post-test (the maximum score is 40)

TABLE III: STUDENT'S FEEDBACK ON DIFFERENT ASPECTS OF COLLABORATIVE CONCEPT MAPPING (USING THE LIKERT SCALE)

\begin{tabular}{|c|c|c|}
\hline $\begin{array}{l}\text { Sr. } \\
\text { no }\end{array}$ & Item & $\begin{array}{l}\% \text { Agree or } \\
\text { Strongly Agree }\end{array}$ \\
\hline 1 & $\begin{array}{l}\text { Collaborative concept mapping method is } \\
\text { new and interesting. }\end{array}$ & 93.18 \\
\hline 2 & $\begin{array}{l}\text { Collaborative concept mapping helped me to } \\
\text { connect the various concepts and contents } \\
\text { better }\end{array}$ & 84.09 \\
\hline 3 & $\begin{array}{l}\text { Collaborative concept maps are difficult to } \\
\text { draw and understand }\end{array}$ & 15.90 \\
\hline 4 & $\begin{array}{l}\begin{array}{l}\text { Collaborative concept maps are time } \\
\text { consuming }\end{array} \\
\end{array}$ & 18.18 \\
\hline 5 & $\begin{array}{l}\text { Collaborative concept maps help in } \\
\text { participating in discussions }\end{array}$ & 86.36 \\
\hline 6 & $\begin{array}{l}\text { This activity of concept mapping helped me } \\
\text { in problem solving capacity }\end{array}$ & 65.90 \\
\hline 7 & $\begin{array}{l}\text { Collaborative concept maps helped me to } \\
\text { rectify the misconceptions about the topic }\end{array}$ & 54.54 \\
\hline 8 & $\begin{array}{l}\text { Collaborative concept mapping activity is } \\
\text { useful in understanding in } \\
\text { memorizing/recalling/visualizing the various } \\
\text { key concepts }\end{array}$ & 65.90 \\
\hline 9 & $\begin{array}{l}\text { Collaborative concept mapping helped me to } \\
\text { see a 'Big picture' of the topic }\end{array}$ & 81.81 \\
\hline 10 & $\begin{array}{l}\text { Collaborative concept mapping activity is } \\
\text { useful to me to apply to other subjects in the } \\
\text { near future }\end{array}$ & 79.54 \\
\hline 11 & $\begin{array}{l}\text { Collaborative concept maps helped to } \\
\text { improve the quality of concept maps }\end{array}$ & 84.09 \\
\hline
\end{tabular}




\section{Students' AtTitudes toward the Collaborative CONCEPT MAP}

The attitudes of students towards concept mapping are summarized in Table III. Many students (93\%) feel that the learning with collaborative concept-mapping method is a new and interesting experience for them. Furthermore, collaborative learning can motivate the students $(86 \%)$ to participate in the learning process in order to achieve the same goal. In collaborative concept maps, they are participating in discussions $(86 \%)$. While participating in discussions, they can communicate, explain, and debate on their thinking with peers so as to form the process of cognitive reconstruction and refine knowledge construction. Most of the students (84\%) after experiencing the collaborative concept maps consider that the teaching method can help understand some concepts and contents better in IICE learning. During the interaction, the more capable students can assist the slow learners. However, a small number of students $(16 \%)$ felt it was troublesome to draw concept maps since the students were unfamiliar with using collaborative concept mapping in the beginning. A very few students (18\%) think that drawing concept maps is difficult and consumes too much time to do it.

\section{DISCUSSION AND CONCLUSIONS}

The present findings show that that computer based collaborative generation of concept maps during study time positively affects IICE learning and can be facilitative. The collaborative concept mapping process facilitated the fundamental constructivist requirement that learners be allowed to manage, construct, and share their own understanding of the content. No two maps were alike even though they treated similar content. We believe that concept mapping and collaborative learning techniques complement one another. Concept mapping helps in the external representation of ideas. Collaborative learning, through its emphasis on dialogue and discussion facilitates it further.

Research findings do support the assumption that collaborative learning is more effective than learning individually. Students feel that 'Inspiration' software which supported their construction of concept maps for IICE helped them to organize concepts for meaningful learning. These findings also support the claim that constructivist learning theory is correct regarding learners' needs to organize and represent concepts visually and explore interrelationships among concepts. Social construction of meaning using concept maps was more effective than individual concept map strategy.

The results do support the assumption that collaborative knowledge construction is more effective than individual knowledge construction [17], [31]-[35]. The students in the collaborative group did score significantly higher than the students in the control group. This is most likely be due to the fact that they have worked in a disciplined, supportive collaborative working environment. Learning requires a quiet phase of knowledge acquisition and comprehension, it also benefits from the interaction with others who are trying to achieve the same goal. Collaboration is seen as a result of successful interaction between students, only when the participants agree on a majority of issues or agree to disagree. Chiu, Wu, and Huang, (2000) have suggested that when students have computer skills and collaboration skills, they can work together effectively on computers [36].

Generating concept mapping in groups can improve the learning performance rather than working independently. Working in collaboration helps students exchange their ideas and learn from each other. During the interaction, high ability students can assist the slow learners through discussion and persuasion. Thus, slow learners can refine their concept mapping abilities. One must also be aware of the situation that in collaborative learning some students only copy others concept maps without understanding concepts. Collaborative concept mapping helps teachers to identify and correct students' mistakes or misconceptions.

This study also notices some limitations from the students' negative views on generating concept maps because they found it was time consuming and difficult to draw on computers. Another limitation of the study is the relatively small number of participants. Thus, the results are limited to inference. Therefore, a more in-depth research on exploring the effects of incorporating collaborative concept mapping on participants with different genders (males or females) or differing student's abilities (high or low achievement of students) has been suggested for future research. Collaborative concept-mapping could increase the learning and research experience of mechanical engineering students and teachers and teachers from other disciplines, and also serve as useful a reference for other teachers from other institutes.

\section{REFERENCES}

[1] C. C. Bonwell and J. A. Eison, "Active learning: Creating excitement in the classroom," ASHEERIC Higher Education Report No. 1, George Washington University, Washington, DC, 1991.

[2] D. H. Jonassen, "Semantic networking as cognitive tool," Cognitive Tools for Learning, pp. 12-22, Berlin: Springer, 1992.

[3] R. A. Santiago, L. A. Gabriela, and S. L. M. Carlos, "Fostering multimedia learning with collaborative concept mapping: The effect of cognitive aid on performance and on collaboration," International Journal of Higher Education, vol. 3, no. 2, 2014.

[4] N. Saab, W. R. Joolingen, and B. Hout-Wolters, "Support of the collaborative inquiry learning process: Influence of support on task and team regulation," Metacognition and Learning, vol. 7, 2012, pp. 7-23.

[5] G. J. Hwang, P. H. Wu, and H. R. Ke, "An interactive concept map approach to supporting mobile learning activities for natural science courses," Computers and Education, vol. 57, 2011, pp. 2272-2280.

[6] P-L. Liu, C.-J. Chen, and Y-J. Chang, "Effects of a computer-assisted concept mapping learning strategy on EFL college students' English reading comprehension," Computers and Education, vol. 54, no. 2, 2010, pp.436-445.

[7] K. E. Chang, Y.-T. Sung, and S.-F. Chen, "Learning through computer based concept mapping with scaffolding aid," Journal of Computer Assisted Learning, vol. 17, no. 1, pp. 21-33, 2001.

[8] Duffy T. M., Lowyck, J., and Jonassen, D. H., Designing Environment For Constructive Learning, New York: Springer, 1991.

[9] L. Anderson-Inman and L. Zeitz, "Computer-based concept mapping: Active studying for active learners," The Computer Teacher, vol. 21, no. 1,1993 , pp. 10-11.

[10] J. D. Novak and A. J. Cañas, The Theory Underlying Concept Maps and How to Construct Them, Institute for Human and Machine Cognition, 2006.

[11] D. Hyerle, A Field Guide To Using Visual Tools, Alexandria, VA Association for Supervision and Curriculum Development, 2000.

[12] J. D. Novak and D. B. Gowin, Learning How to Learn, London: Cambridge University, 1984.

[13] J. J. Mintzes, J. H. Wandersee, and J. D. Novak, Teaching Science for Understanding, San Diego, CA: Academic Press, 1997. 
[14] J. D. Novak, "Meaningful learning: the essential factor for conceptual change in limited or appropriate propositional hierarchies (LIPHs) leading to empowerment of learners," Science Education, vol. 86, no. 4 2002, pp. 548-571.

[15] L. R. McClure, B. Sonak, and H. K. Suen, "Concept map assessment of classroom learning: Reliability, validity, and logistical practicality," Journal of Research in Science Teaching, vol. 36, pp. 475-492, 1999.

[16] M. A. Ruiz-Primo and R. Shavelson, "Problems and issues in the use of concept maps in science assessment," Journal of Research in Science Teaching, vol. 33, pp. 569-600, 1996.

[17] F. Fischer, J. Bruhn, C. Rasel, and H. Mandl, "Fostering collaborative knowledge construction with visualization tools," Learning and Instruction, vol. 12, 2002, pp. 213-232.

[18] A. T. Lumpe and J. R. Staver, "Peer collaboration and concept development: Learning about photosynthesis," Journal of Research in Science Teaching, vol. 32, 1995.

[19] D. P. Brandon and A. B. Holingshead, "Collaborative learning and computer-supported groups," Communication Education, vol. 48, no. 2, 1999, pp. 109-126.

[20] N. Stoyanova and P. Kommers, "Concept mapping as medium of shared cognition in computer-supported collaborative problem solving," Journal of Interactive Learning Research, vol. 13, no. 1-2, pp. 111-133, 2002.

[21] C. Boxtel, J. L. Linden, and G. Kanselaar, "Collaborative construction of conceptual understanding: interaction processes and learning outcomes emerging from a concept mapping and poster task," Journal of Interactive Learning Research, vol. 3-4, pp. 341-361, 1997.

[22] J. Linden, G. Erkens, H. Schmidt, and P. Renshaw, "Collaborative learning," New Learning, Dordrecht: Kluwer Academic Publishers, 2000, pp. 37-57.

[23] C. Boxtel, J. L. Linden, E. Roelofs, and G. Erkens, "Collaborative concept mapping: Provoking and supporting meaningful discourse," Theory into Practice, vol. 41, no. 1, 2002, pp. 40-46.

[24] L. Anderson-Inman and L. Ditson, "Computer-based concept mapping A tool for negotiating meaning," Learning and Leading with Technology, vol. 26, no. 8, 1999, pp. 6-13.

[25] K. M. Fischer, "Semantic-networking: The new kid on the block," Journal of Research in Science Teaching, vol. 27, pp. 1002-1018, 1990.

[26] R. Royer and J. Royer, "Comparing hand drawn and computer generated concept mapping," Journal of Computers in Mathematics and Science Teaching, vol. 23, no. 1, pp.67-81, 2004.

[27] D. H. Jonassen, C. Carr, and H. P. Yueh, "Computers as mind tools for engaging learners in critical thinking," Tech Trends, vol. 43, no. 2, pp. 24-32, 1998.

[28] D. H. Jonassen, Computer as Mindtools for Schools: Engaging Critical Thinking, Upper Saddle River, NJ: Prentice Hall, 2000.

[29] L. Anderson-Inman, "Computer-assisted outlining: Information organization made easy," Journal of Adolescent and Adult Literacy, vol. 39, no. 4, pp. 316-320, 1996.

[30] H. Gao, E. Shen, S. Losh, and J. Turner, "A review of studies on collaborative concept mapping: What have we learned about the technique and what is next?" Journal of Interactive Learning Research, vol. 18, no. 4, pp. 479-492, 2007.

[31] M. Haugwitz, J. Nesbit, and A. Sandmann, "Cognitive ability and the instructional efficacy of collaborative concept mapping," Learning and Individual Differences, vol. 20, 2010, pp. 536-543.

[32] W. M. Roth and A. Roychoudhury, "The concept map as a tool for the collaborative construction of knowledge," Journal of Research in Science Teaching, vol. 30, pp. 503-534, 1993.

[33] L. Wellington and L. Osborne, Language and Literacy in Science Education, Philadelphia: Open University Press, 2001

[34] Y. Yin, J. Vanides, M. A. Ruiz-Primo, C. Ayala, and R. L. Shavelson, "Comparison of two concept-mapping techniques: Implications for scoring, interpretation, and use," Journal of Research in Science Teaching, vol. 42, pp. 166-184, 2005.

[35] J. D. Novak, Learning, Creating and Using Knowledge: Concept Maps as Facilitative Tools in Schools And Corporations, Mahwah, NJ: Lawrence Erlbaum, 1998.

[36] K.-E. Chang, Y. T. Sung, and S.-F. Chen, "The effect of concept mapping to enhance text comprehension and summarization," The Journal of Experimental Education, vol. 71, no. 1, pp. 5-23, 2002.

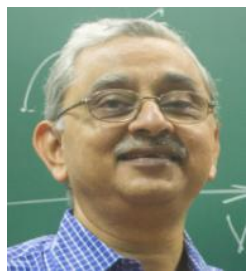

Uday N. Gaitonde is professor of mechanical engineering at Indian Institute of Technology Bombay, Mumbai, India. He has over 35 years of teaching and research experience in various fields of thermal engineering. His research interests include experimental and numerical studies in heat transfer, energy conversion, and power plant dynamics. He is involved in teaching methodology in thermodynamic $\mathrm{s}$ and had conducted a MOOC on Thermodynamics on the edX and IIT Bombay X platforms.

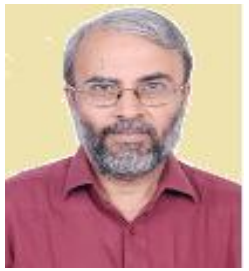

Bhalachandra L. Tembe is a professor of chemistry and an associate member of the interdisciplinary group in educational technology at the Indian Institute of technology Bombay, India. He has 33 years of teaching and research experience in physical and theoretical chemistry, statistical mechanics and molecular dynamics.

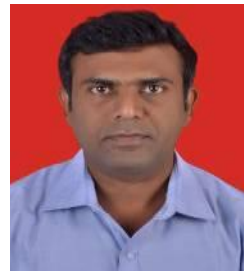

Sachin K. Kamble is a research fellow in Indian Institute of Technology, Bombay, India. He is an associate professor, the head of Mechanical Engineering Department and in-charge principal at the Chhatrapati Shivaji Maharaj Institute of Technology, Panvel, India. His Research interests include concept maps, instructional design models, thermodynamics and internal combustion engines. 